\title{
Synthesis and Structural Properties of Type I Potassium SiGe Alloy Clathrates
}

Lakshmi Krishna ${ }^{\text {a }}$, Ping Chai ${ }^{b}$, Carolyn A. Koh ${ }^{c}$, Eric S. Toberer ${ }^{\text {a }}$, George S. Nolas ${ }^{\text {b \# }}$

${ }^{a}$ Department of Physics, Colorado School of Mines, Golden, CO, USA

${ }^{b}$ Department of Physics, University of South Florida, Tampa, FL, USA

${ }^{c}$ Department of Chemical and Biological Engineering, Colorado School of Mines, Golden, CO, USA

We report on the synthesis and structural characterization of type I SiGe alloy clathrates, with potassium as the guest species, synthesized by thermal decomposition and kinetically controlled thermal decomposition from $\mathrm{K}_{4}\left(\mathrm{Si}_{1-x} \mathrm{Ge}_{x}\right)_{4}$ precursor phases with $x=0.1,0.3$, and 0.75 . The $\mathrm{K}_{8}\left(\mathrm{Si}_{1-x} \mathrm{Ge}_{x}\right)_{46}$ clathrates were structurally characterized by X-ray diffraction. Rietveld refinement on the XRD data indicated that Ge preferentially occupies the $24 k$ and $6 c$ sites for $x<$ 0.5 but preferentially occupies the $16 i$ and $24 k$ sites for $x>0.5$.

* Email: Ikrishna@mines.edu

\# Email: gnolas@usf.edu 


\section{Introduction}

Inorganic clathrate compounds have open-framework crystal structures wherein the host framework encapsulates "guest" species. Typically, the framework is made up of Group 14 elements (X) with interstitial elements (A) made up of alkali, alkaline earth, rare-earth, tellurium, and halogen elements [1]. Due to their chemical diversity and structural features clathrates are of interest for a diverse range of potential applications, including thermoelectrics [2], superconductors [3], photovoltaics [4,5], and lithium-ion batteries [6].

The type I clathrate unit cell can be thought of as being formed by two different types of polyhedra, two 24 atom and six 20 atom polyhedron, resulting in an $\mathrm{A}_{8} \mathrm{X}_{46}$ stoichiometric composition. Type I Si and Ge clathrates encapsulating potassium guest atoms, $\mathrm{K}_{8} \mathrm{Si}_{46}$ and $\mathrm{K}_{8} \mathrm{Ge}_{44}$, are most commonly synthesized by thermal decomposition of the precursor phase $\mathrm{K}_{4} \mathrm{Si}_{4}$ and $\mathrm{Ke}_{4} \mathrm{Ge}_{4}$, respectively [7-9]. Recently Stefanoski et al. reported the single crystal growth of both type I and II silicon clathrates with potassium guest atoms by kinetically controlled thermal decomposition $[10,11]$. In this technique the alkali metal vapor formed during the thermal decomposition process is absorbed by a graphite layer that modifies the local vapor pressure to control the reaction kinetics. Oxidation of the precursor $\mathrm{K}_{4} \mathrm{Ge}_{9}$ was also used to synthesize type II Ge clathrates [12]. Alloyed SiGe clathrates are of fundamental interest as they allow for (a) modifying the band structure and that could result in tuning the electrical properties [13] and (b) enhancement of thermoelectric properties [14]. Synthesis of alloyed SiGe clathrates encapsulating alkali or alkaline earth guest have been reported $[1,4,15,16]$. Prior work on type I alloyed SiGe clathrates has investigated variation in thermoelectric performance as a result of framework alloying [14, 16-18], however, the SiGe alloying fraction was varied only over a narrow range. Ramachandran et al. reported on synthesis of 50 at.\% SiGe alloyed clathrate with 
potassium guest via thermal decomposition of Zintl precursor phase but the resulting clathrate had poor crystallinity [15] . In this work we report on the synthesis of three new compositions of alloyed $\mathrm{SiGe}$ type I clathrates $\left(\mathrm{K}_{8}\left(\mathrm{Si}_{1-x} \mathrm{Ge}_{x}\right)_{46}\right.$ with $\mathrm{x}=0.1,0.3$ and 0.75$)$ from Zintl precursor phases $\mathrm{K}_{4}\left(\mathrm{Si}_{1-x} \mathrm{Ge}_{x}\right)_{4}$ by thermal decomposition and kinetically controlled thermal decomposition process and perform structural characterization. The Si-Ge tetrahedrons in these precursors presumably allow for clathrate formation [16] as is the case of $\left[\mathrm{Si}_{4}\right]^{4-}$ in $\mathrm{Na}_{4} \mathrm{Si}_{4}$ for silicon clathrate formation [1].

\section{Experimental}

The $\mathrm{Si}_{1-x} \mathrm{Ge}_{x}$ diamond phase alloys were synthesized by mechanical alloying stoichiometric amounts of silicon (Alfa, $99.9999 \%$ ) and germanium (Alfa, 99.9999\%) as described in Baranowski et al [4]. For the preparation of the Zintl precursors, $\mathrm{K}_{4}\left(\mathrm{Si}_{1-x} \mathrm{Ge}_{x}\right)_{4}$, elemental potassium and ball milled $\mathrm{Si}_{1-x} \mathrm{Ge}_{x}$ alloys were weighed in 1.4: 1 molar ratio, placed in a ceramic crucible, covered with aluminum foil and subsequently placed in a quartz tube before heated to $395{ }^{\circ} \mathrm{C}$ for $24 \mathrm{~h}$ under flowing Ar. The precursor synthesis technique employed in this work was relatively simple and achieved without need of sealing the crucible (typically tantalum or niobium) containing the potassium plus $\mathrm{Si}_{1-x} \mathrm{Ge}_{x}$ mixtures. Extreme care should be taken while handling elemental potassium and the precursors as they are air and moisture sensitive. The thermal decomposition of the precursor, to the clathrate phase, was accomplished by heating at $395^{\circ} \mathrm{C}$ for $48 \mathrm{~h}$ under dynamic vacuum ( $1 \mathrm{~m}$ Torr). Details of the kinetically controlled thermal decomposition technique can be found in Ref. 10. In this technique, the precursor $\left(\mathrm{K}_{4}\left(\mathrm{Si}_{1-x} \mathrm{Ge}_{x}\right)_{4}\right)$ is sandwiched between two layers of graphite flakes, subjected to uniaxial pressure and heated to undergo thermal decomposition to clathrate phase. $\mathrm{NaCl}$ is used between the precursor and the graphite flake to prevent adhesion of the clathrate crystals to the flake and to allow alkali metal 
to be transported in the vapor phase [10]. Here $\mathrm{K}_{4}\left(\mathrm{Si}_{1-x} \mathrm{Ge}_{x}\right)_{4}$ with $x=0.1,0.3$, and 0.75 were heated to $550^{\circ} \mathrm{C}$ for $8 \mathrm{~h}, 530^{\circ} \mathrm{C}$ for $8 \mathrm{~h}$, and $485^{\circ} \mathrm{C}$ for $5 \mathrm{~h}$, respectively, to obtain the type I alloy clathrates. After decomposition process, all the samples were washed with ethanol to remove any residual potassium. Extreme caution should be taken while washing the sample with ethanol and this process should be carried out in an inert atmosphere. The final clathrate compounds are stable in air.

The phase purity and crystal structure of the specimens were determined by powder X-ray diffraction (XRD) at room temperature by a Bruker D8 Focus diffractometer in Bragg-Brentano geometry using $\mathrm{Cu} \mathrm{K} \alpha$ radiation and a graphite monochromator. The XRD patterns were obtained between $10^{\circ}$ and $100^{\circ}$ in steps of $0.01^{\circ}$ with a counting rate of $1^{\circ}$ per minute. Rietveld refinement was accomplished using the GSAS suite of programs [21]. The initial positional parameters were obtained from the data previously reported for $\mathrm{K}_{8} \mathrm{Si}_{46}$ [22]. For refinement of the SiGe alloy clathrates, the Si plus Ge occupancy was constrained to 1 for each of the three framework sites $(6 c, 16 i, 24 k)$.

\section{Results and Discussion}

The measured and simulated XRD patterns and the difference profiles for the clathrates prepared by thermal decomposition are shown in Fig. 1 and the refinement parameters are listed in Table 1. XRD patterns for the alloyed precursors are provided in the supplementary section. Alloys synthesized by conventional thermal decomposition and kinetically controlled thermal decomposition process are labelled a to e and a1 to c1, respectively. Phase pure $\mathrm{K}_{8} \mathrm{Si}_{17.6} \mathrm{Ge}_{28.4}$ (d) was obtained, $\mathrm{K}_{8} \mathrm{Si}_{46}$ (a) and $\mathrm{K}_{8} \mathrm{Si}_{41.3} \mathrm{Ge}_{4.7}$ (b) contained trace amounts of $\alpha-\mathrm{Si}_{1} \mathrm{~K}_{6.9} \mathrm{Si}_{28.5} \mathrm{Ge}_{17.5}$ (c) contained $\sim 10 \mathrm{wt} \% \alpha-\mathrm{Si}$ plus a trace amount of an unidentified phase, and $\mathrm{K}_{8} \mathrm{Ge}_{44}$ (e) contained 
amorphous phase. All atomic positions are fully occupied for $\mathrm{K}_{8} \mathrm{Si}_{46}$ (a) while vacancies exist on the framework $6 c$ site for $\mathrm{K}_{8} \mathrm{Ge}_{44}$ (e), consistent with that of previous reports [9, 23]. Rietveld refinements were carried out to investigate the presence of Ge framework vacancies in alloyed SiGe clathrates. But this could not be definitely answered from the conventional XRD data. Hence we constricted the $\mathrm{Si}$ plus Ge occupancy to be one. For $\mathrm{K}_{8} \mathrm{Si}_{41.3} \mathrm{Ge}_{4.7}$ (b), the Si-to-Ge ratio was close to that of the precursor while $\mathrm{K}_{6.9} \mathrm{Si}_{28.5} \mathrm{Ge}_{17.5}$ (c) and $\mathrm{K}_{8} \mathrm{Si}_{17.6} \mathrm{Ge}_{28.4}$ (d) had a higher and lower Ge content, respectively, than that of the precursors. As in other clathrate compounds [24-26], preferential site occupancy was observed. The refinement results indicate that germanium preferentially occupies the $24 k$ and $6 c$ sites when the Ge content was below $50 \%$ and the $16 i$ and $24 k$ site when the Ge content was above $50 \%$. We also note vacancies at the $2 a$ site for $\mathrm{K}_{6.9} \mathrm{Si}_{28.5} \mathrm{Ge}_{17.5}$, as previously reported for other potassium-containing clathrates [23, 27]. The SiGe alloy clathrates were also synthesized by kinetically controlled thermal decomposition. The XRD patterns and refinement results are shown in Fig. 2 and Table 1, respectively. The Sito-Ge ratios of the clathrate phases are closer to that of the precursors and the site occupancy for the $\mathrm{Si} / \mathrm{Ge}$ framework follows the same trend as that exhibited by the clathrates prepared by thermal decomposition (Table 1). The $\mathrm{K}_{7.6} \mathrm{Si}_{14.9} \mathrm{Ge}_{31.1}$ (c1) specimen also contained amorphous phase. The lattice constants with Ge concentration for all clathrates compounds are shown in Fig. 3 and obey Vegard's law, exhibiting a linear increase with increasing germanium content. The two compounds with vacancies on the K $2 a$ site deviate slightly from Vegard's law (Fig. 3). Note that in order to investigate the presence of framework vacancies on alloyed clathrates further experimental characterization is warranted.

\section{Conclusions}




\section{Acknowledgements}

LK, CAK and ES would like to thank the support of REMRSEC- seed grants (DMR0820518) for funding the work carried out in this project. PC and GSN acknowledge support by the U.S. Department of Energy, Basic Energy Sciences, Division of Materials Science and Engineering, under Award No. DE-FG02-04ER46145 for powder XRD measurements and structural refinement, and synthesis employing kinetically controlled thermal decomposition. 


\begin{tabular}{|c|c|c|c|c|c|}
\hline \multicolumn{6}{|c|}{ Thermal Decomposition } \\
\hline Precursor & $\mathrm{KSi}$ & $\mathrm{KSi}_{0.9} \mathrm{Ge}_{0.1}$ & $\mathrm{KSi}_{0.7} \mathrm{Ge}_{0.3}$ & $\mathrm{KSi}_{0.25} \mathrm{Ge}_{0.75}$ & $\mathrm{KGe}$ \\
\hline Nominal composition & $\mathrm{K}_{8} \mathrm{Si}_{46}$ & $\mathrm{~K}_{8} \mathrm{Si}_{41.4} \mathrm{Ge}_{4.6}$ & $\mathrm{~K}_{8} \mathrm{Si}_{32.2} \mathrm{Ge}_{13.8}$ & $\mathrm{~K}_{8} \mathrm{Si}_{11.5} \mathrm{Ge}_{34.4}$ & $\mathrm{~K}_{8} \mathrm{Ge}_{46}$ \\
\hline Refined composition & $\mathrm{K}_{8} \mathrm{Si}_{46}$ & $\mathrm{~K}_{8} \mathrm{Si}_{41.3} \mathrm{Ge}_{4.7}$ & $\mathrm{~K}_{6.9} \mathrm{Si}_{28.5} \mathrm{Ge}_{17.5}$ & $\mathrm{~K}_{8} \mathrm{Si}_{17.6} \mathrm{Ge}_{28.4}$ & $\mathrm{~K}_{8} \mathrm{Ge}_{44}$ \\
\hline$a(\AA)$ & $10.2830(1)$ & $10.3149(2)$ & $10.3540(1)$ & $10.5546(6)$ & $10.6715(1)$ \\
\hline $\mathrm{V}\left(\AA^{3}\right)$ & $1087.34(3)$ & $1097.46(5)$ & $1110.00(5)$ & $1175.8(2)$ & $1215.31(3)$ \\
\hline Occup. K $(2 a)$ & 1 & 1 & $0.462(9)$ & 1 & 1 \\
\hline Occup. K $(6 d)$ & 1 & 1 & 1 & 1 & 1 \\
\hline Occup. $\mathrm{Si} / \mathrm{Ge}(6 c)$ & $1 / 0$ & $0.882(5) / 0.118(5)$ & $0.428(5) / 0.572(5)$ & $0.608(4) / 0.392(4)$ & $0 / 0.674(4)$ \\
\hline Occup. Si/Ge (16i) & $1 / 0$ & $0.985(5) / 0.015(5)$ & $0.764(5) / 0.236(5)$ & $0.505(5) / 0.495(5)$ & $0 / 1$ \\
\hline Occup.Si/Ge (24k) & $1 / 0$ & $0.843(4) / 0.157(4)$ & $0.571(5) / 0.429(5)$ & $0.246(5) / 0.754(5)$ & $0 / 1$ \\
\hline $\mathrm{Rp}(\%)$ & 3.57 & 3.08 & 2.58 & 3.06 & 1.77 \\
\hline$w \operatorname{Rp}(\%)$ & 5.89 & 4.54 & 3.79 & 4.10 & 2.32 \\
\hline$\chi^{2}$ & 5.644 & 4.048 & 3.241 & 4.683 & 1.6 \\
\hline \multicolumn{6}{|c|}{ Kinetically Controlled Thermal Decomposition } \\
\hline \multicolumn{2}{|l|}{ Precursor } & $\mathrm{KSi}_{0.9} \mathrm{Ge}_{0.1}$ & $\mathrm{KSi}_{0.7} \mathrm{Ge}_{0.3}$ & \multicolumn{2}{|l|}{$\mathrm{KSi}_{0.25} \mathrm{Ge}_{0.75}$} \\
\hline \multicolumn{2}{|l|}{ Nominal composition } & $\mathrm{K}_{8} \mathrm{Si}_{41.4} \mathrm{Ge}_{4.6}$ & $\mathrm{~K}_{8} \mathrm{Si}_{32.2} \mathrm{Ge}_{13.8}$ & \multicolumn{2}{|l|}{$\mathrm{K}_{8} \mathrm{Si}_{11.5} \mathrm{Ge}_{34.4}$} \\
\hline \multicolumn{2}{|l|}{ Refined composition } & $\mathrm{K}_{8} \mathrm{Si}_{41.4} \mathrm{Ge}_{4.6}$ & $\mathrm{~K}_{8} \mathrm{Si}_{34.8} \mathrm{Ge}_{11.2}$ & \multicolumn{2}{|l|}{$\mathrm{K}_{7.59} \mathrm{Si}_{14.9} \mathrm{Ge}_{31.1}$} \\
\hline \multicolumn{2}{|l|}{$a(\AA)$} & $10.2935(1)$ & $10.3598(1)$ & \multicolumn{2}{|l|}{$10.4680(6)$} \\
\hline \multicolumn{2}{|l|}{$\mathrm{V}\left(\AA^{3}\right)$} & $1090.66(4)$ & $1111.87(4)$ & \multicolumn{2}{|l|}{$1147.1(2)$} \\
\hline \multicolumn{2}{|l|}{ Occup. K (2a) } & 1 & 1 & \multicolumn{2}{|l|}{$0.80(4)$} \\
\hline \multicolumn{2}{|l|}{ Occup. K $(6 d)$} & 1 & 1 & \multicolumn{2}{|l|}{1} \\
\hline \multicolumn{2}{|l|}{ Occup. Si/Ge(6c) } & $0.887(4) / 0.113(4)$ & $0.642(5) / 0.358(5)$ & \multicolumn{2}{|l|}{$0.59(2) / 0.41(1)$} \\
\hline \multicolumn{2}{|l|}{ Occup. Si/Ge (16i) } & $0.946(5) / 0.054(5)$ & $0.883(6) / 0.117(6)$ & \multicolumn{2}{|l|}{$0.43(3) / 0.57(3)$} \\
\hline \multicolumn{2}{|l|}{ Occup. $\mathrm{Si} / \mathrm{Ge}(24 k)$} & $0.871(4) / 0.129(4)$ & $0.701(4) / 0.299(4)$ & \multicolumn{2}{|l|}{$0.19(3) / 0.81(1)$} \\
\hline \multicolumn{2}{|l|}{$\mathrm{Rp}(\%)$} & 2.88 & 2.81 & \multicolumn{2}{|l|}{2.27} \\
\hline \multicolumn{2}{|l|}{$w \operatorname{Rp}(\%)$} & 3.90 & 3.67 & \multicolumn{2}{|l|}{3.01} \\
\hline \multicolumn{2}{|l|}{$\chi^{2}$} & 2.278 & 2.224 & \multicolumn{2}{|l|}{1.671} \\
\hline
\end{tabular}




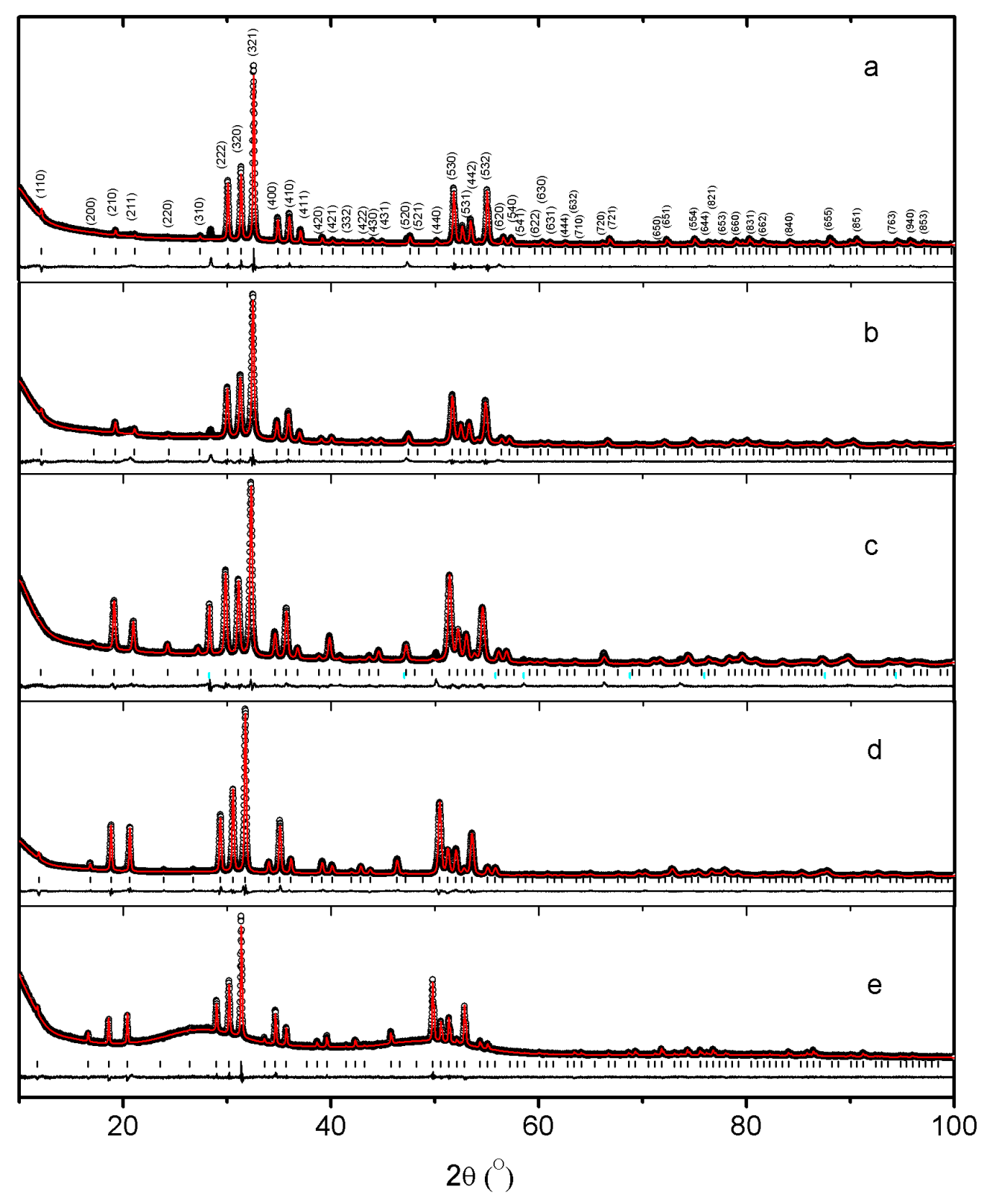

Fig. 1. Measured (empty circles) and simulated (solid red lines) powder XRD patterns for clathrates (a) $\mathrm{K}_{8} \mathrm{Si}_{46}$, (b) $\mathrm{K}_{8} \mathrm{Si}_{41.3} \mathrm{Ge}_{4.7}$, (c) $\mathrm{K}_{6.92} \mathrm{Si}_{28.5} \mathrm{Ge}_{17.5}$, (d) $\mathrm{K}_{8} \mathrm{Si}_{17.6} \mathrm{Ge}_{28.4}$, and (e) $\mathrm{K}_{8} \mathrm{Ge}_{44}$ synthesized by thermal decomposition. The difference between the observed and simulated plots is shown at the bottom of each pattern. Vertical tick marks represent allowed reflections. The cyan tick marks in (c) indicate peaks from $\alpha-S i$. 


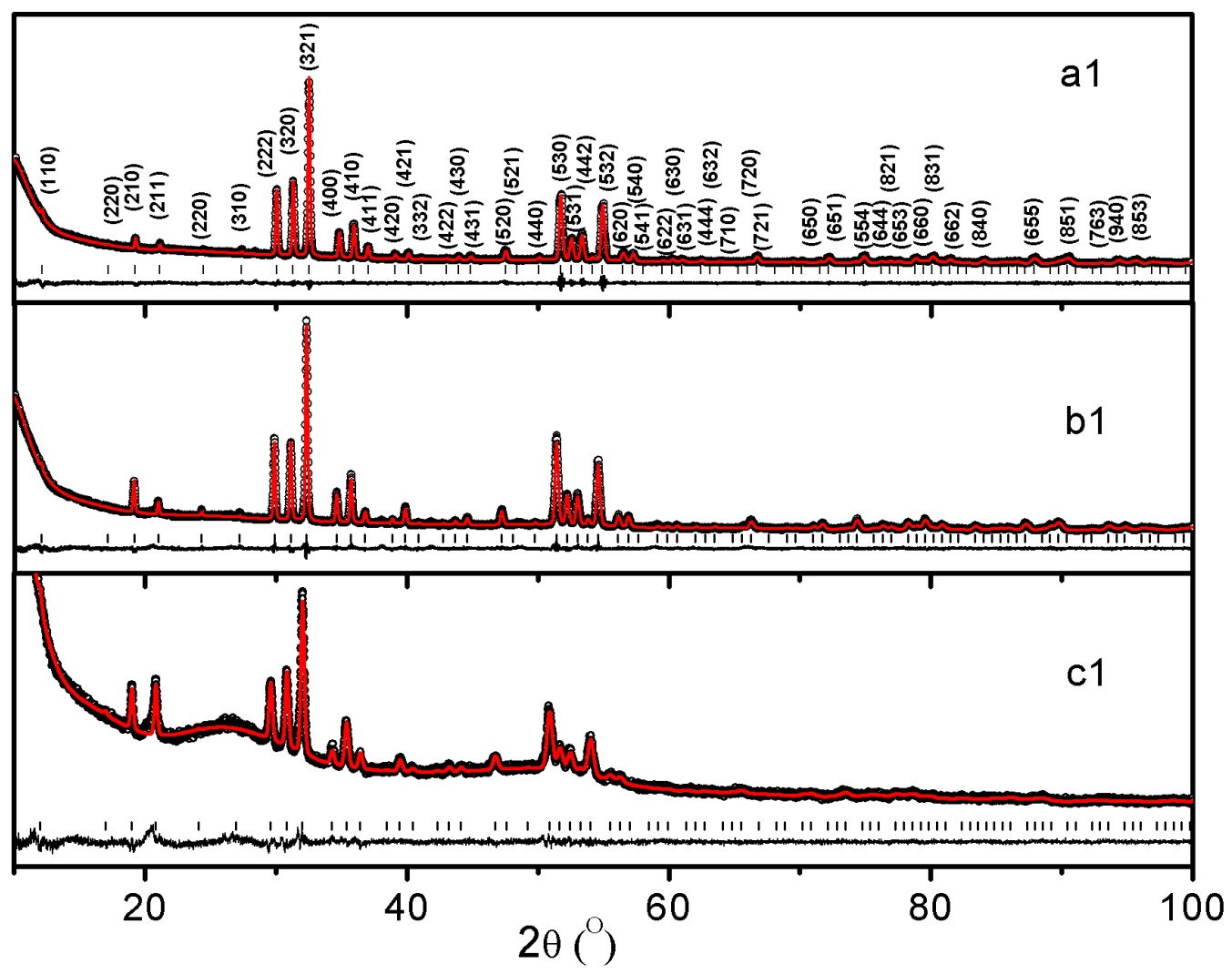

Fig. 2. Measured (empty circles) and simulated (solid red lines) powder XRD patterns for (a1) $\mathrm{K}_{8} \mathrm{Si}_{41.4} \mathrm{Ge}_{4.6}$, (b1) $\mathrm{K}_{8} \mathrm{Si}_{34.8} \mathrm{Ge}_{11.2}$, and (c1) $\mathrm{K}_{7.6} \mathrm{Si}_{14.9} \mathrm{Ge}_{31.1}$ synthesized by kinetically controlled thermal decomposition. 


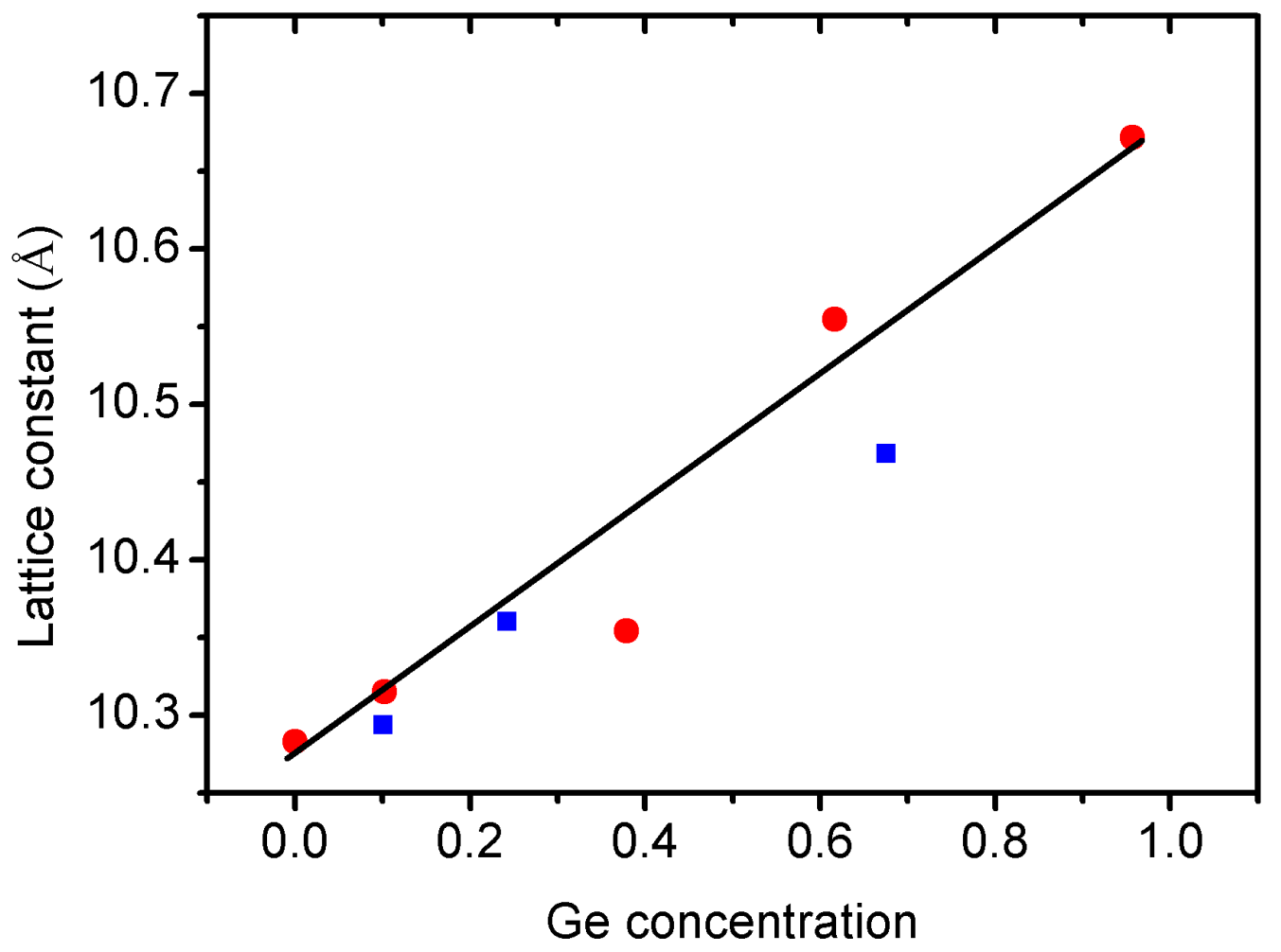

Fig. 3. Lattice constant as a function of Ge concentration for the clathrates prepared by thermal decomposition (red) and kinetically controlled thermal decomposition (blue). 


\section{References}

[1] Nolas GS. The Physics and Chemistry of Inorganic Clathrates, Springer Series on Materials Volume 199, 2014.

[2] Nolas GS, Cohn JL, Slack GA, Schujman SB. Appl Phys Lett 1998; 73: 178.

[3] Connétable D, Timoshevskii V, Masenelli B, Beille J, Marcus J, Barbara B, et al. Phys Rev Lett 2003; 91: 247001.

[4] Baranowski LL, Krishna L, Martinez AD, Raharjo T, Stevanović V, Tamboli AC, Toberer ES. J Mater Chem C 2014; 17: 3231.

[5] Martinez AD, Krishna L, Baranowski LL, Lusk MT, Toberer ES, Tamboli AC. IEEE. J. Photovolt. 2013; 3: 1305.

[6] Yang J, John ST. J Mater Chem A 2013; 1: 7782.

[7] Cros C, Pouchard M, Hagenmuller P. J Solid State Chem 1970; 2: 570.

[8] Beekman, M.; Nolas, G. S., Int. J Appl. Ceram. Tec. 2007,4 (4), 332-338.

[9] Schnering HG, Llanos J, Peters K, Baitinger M, Grin Y, Nesper R. Z Kristallogr NCS 2011; 226: 9.

[10] Stefanoski S, Beekman M, Wong-Ng W, Zavalij P, Nolas, GS. Chem Mater 2011; 23: 1491.

[11] Stefanoski S, Nolas GS. Cryst Growth Des 2011; 11: 4533.

[12] Guloy AM, Tang Z, Ramlau R, Böhme B, Baitinger M, Grin Y. Eur J Inorg Chem 2009; 2009: 2455.

[13] Moriguchi K, Munetoh S, Shintani A. Phys Rev B 2000; 62: 7138.

[14] Martin J, Nolas GS, Wang H, Yang J. J Appl Phys 2007; 102: 103719.

[15] Ramachandran GK, McMillan PF, Dong J, Gryko J, Sankey OF. Mat. Res. Soc. Proceedings 2002; 626: Z13.2.1-Z13.2.6

[16]Morito H, Momma K, Yamane H. J Alloy Comp 2015; 623:473.

[17]Suekuni K, Avila A M, Umeo K, Takabatake T. Phys. Rev. B 2007; 75:195210

[18]Christensen M, Johnsen S, Sondergaard M, Overgaard J, Birkedal H, Iversen B B. Chem. Mater. 2009; 21: 122-127

[19] Martin J, Erickson S, Nolas GS, Alboni P, Tritt TM, Yang J. J. Appl. Phys. 2006;99:04490

[20] Kasper JS, Hagenmuller P, Pouchard M, Cros C. Science 1965; 150: 1713.

[21] Larson A, Dreele R. General Structure Analysis System (GSAS) program. Rep. No; LA-UR-86748, Los Alamos National Laboratory, Los Alamos, CA: 1994.

[22] Gallmeier J, Schaefer H, Weiss AZ. Naturforsch. B 1967; 22: 1080.

[23] Ramachandran GK, McMillan PF, Dong J, Sankey OF. J Solid State Chem 2000;154: 626.

[24] Wilkinson A, Lind C, Young R, Shastri S, Lee P, Nolas GS Chem Mater 2002; 14:1300.

[25] Beekman M, Wong-Ng W, Kaduk J, Shapiro A, Nolas GS. J Solid State Chem 2007; 180: 1076.

[26] Beekman M, Kaduk J, Gryko J, Wong-Ng W, Shapiro A, Nolas GS. J Alloy Comp 2009; 470: 365.

[27] Boehme B, Guloy A, Tang Z, Schnelle W, Burkardt U, Baitinger M, Grin Y. J Am Chem Soc 2007; 129: 5348. 